\title{
Underwater endoscopic mucosal resection for complete RO removal of an adenoma extending deep into a colonic diverticulum
}

Endoscopic removal of a colorectal polyp involving a diverticulum is challenging owing to the risk of perforation from lack of the muscularis propria [1] and concerns over incomplete resection associated with the difficult access [2].

A 70-year-old man was referred to our department for management of a difficult polyp identified at a previous colonoscopy performed for positive fecal occult blood tests. Colonoscopy revealed a $15-\mathrm{mm}$, flat, elevated polyp extending deep into a diverticulum in the ascending colon. Narrow-band imaging (NBI) magnifying endoscopy was indicative of an adenoma ( $\mathbf{F i g . 1 a ) . ~ I n s p e c t i o n ~ o f ~ t h e ~}$ entire polyp was difficult under $\mathrm{CO}_{2}$ insufflation. Water immersion using the "continuous irrigation” technique with magnifying NBI facilitated identification of the tumor margin within the diverticulum ( Fig. 1 b, c) [3]. A snare tip was fixed in the normal mucosa within the diverticulum and the polyp was introduced into the snare (15-mm Captivator II; Boston Scientific, Tokyo, Japan) using the "rapid water deflation" technique. Underwater endoscopic mucosal resection (UEMR) achieved en bloc removal without per-

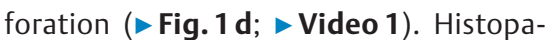
thology revealed a low grade adenoma with negative margins ( $\mathbf{F i g} . \mathbf{2}$ ).

Although complex and time-consuming, traction-assisted endoscopic submucosal dissection (ESD) is efficacious in the management of colonic tumors involving a diverticulum [4]. In UEMR, the "floating" and "heat-sink" effects can facilitate grasping of large or scarred polyps, respectively, and reduce the risk of perforation [5]. In this case, the "continuous irrigation” technique improved polyp visualization within the diverticulum. The "floating" effects could be maximized by the distended colonic wall using the "rapid water deflation" technique to secure the polyp involving the diverticu-

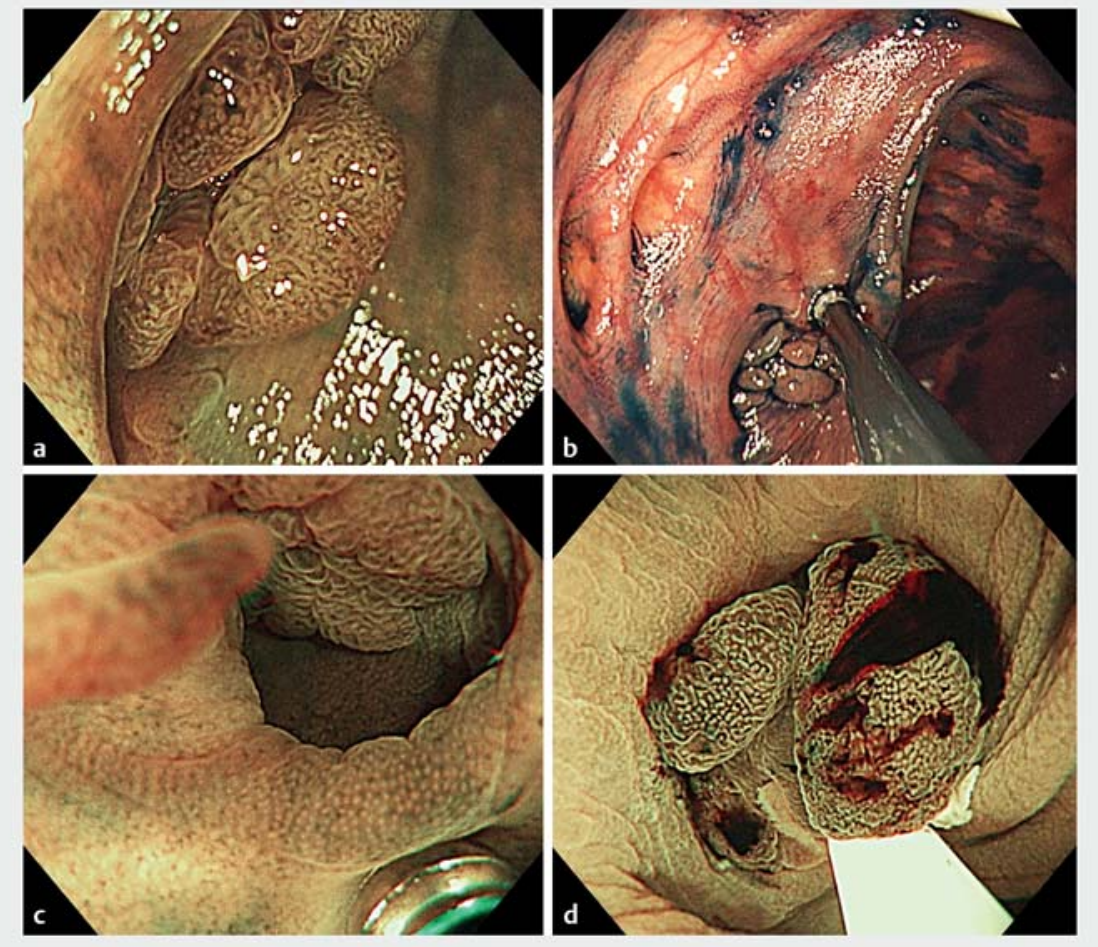

- Fig. 1 Colonoscopic images showing: a a 15-mm, flat, elevated polyp extending into a diverticulum in the ascending colon, where identification of the border of the lesion was difficult owing to its extension into the diverticulum; b good visualization with magnifying narrow-band imaging (NBI) endoscopy with water immersion, which enables identification of the margin of the lesion; $\mathrm{c}$ irregular brown vessels surrounding a tubular white structure on magnifying NBI, suggesting Japan NBI Expert Team (JNET) classification type 2A; $\mathbf{d}$ after the area near the diverticulum has been fixed with a snare tip, the floating effect enabled easy capture of the entire polyp, so that underwater endoscopic mucosal resection (UEMR) could then be performed without any complications.

lum. The "heat-sink" effect decreased the risk of perforation, even for a diverticulum-related polyp. This is the first case demonstrating the usefulness of UEMR in the management of an adenoma extending into a diverticulum. UEMR may be considered for complete removal of adenomas extending into a diverticulum.

Endoscopy_UCTN_Code_TTT_1AQ_2AD
Competing interests

The authors declare that they have no conflict of interest.

The authors

Kazuo Shiotsuki, Kenichiro Imai, Kinichi Hotta, Sayo Ito, Yoshihiro Kishida, Hiroyuki Ono

Division of Endoscopy, Shizuoka Cancer Center, Shizuoka, Japan 


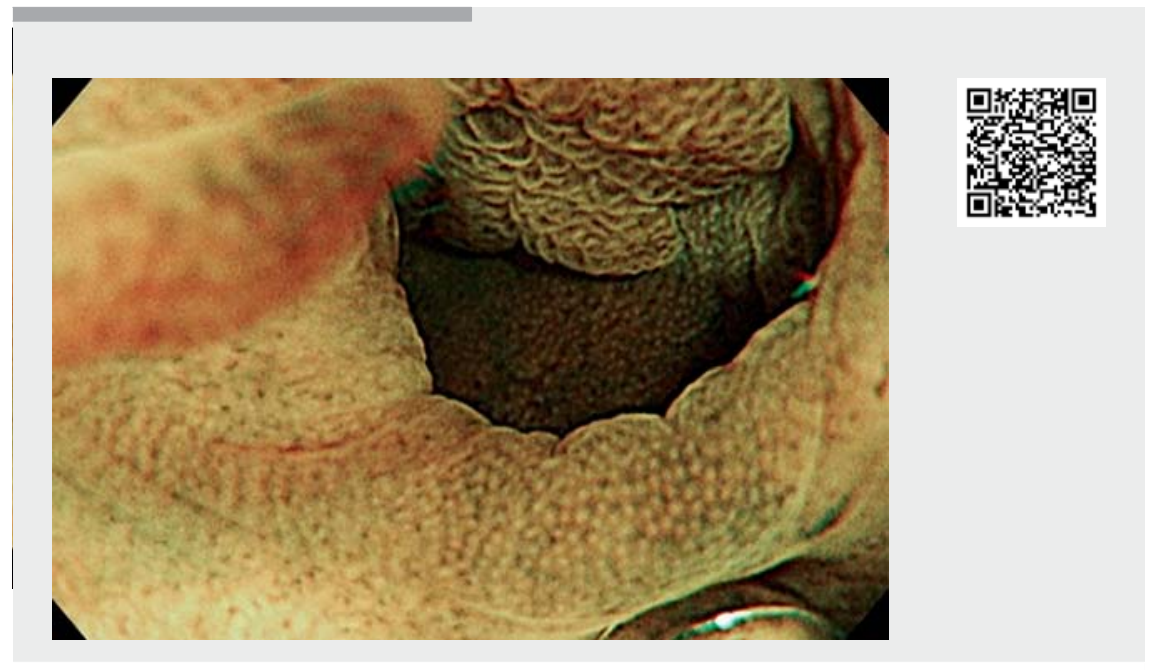

$\checkmark$ Video 1 A 15-mm laterally spreading tumor resected completely by underwater endoscopic mucosal resection. Water immersion enables visualization of the diverticulum margin; furthermore, it facilitates snaring of the entire lesion due to "floating" and "massive deflation."

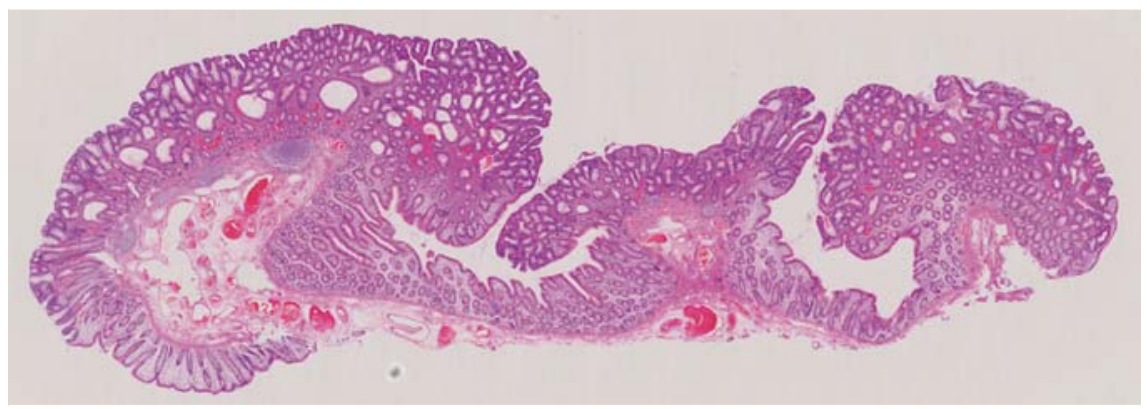

- Fig. 2 Histopathological appearance showing an adenoma with negative resection margins.

\section{Corresponding author}

\section{Kenichiro Imai, MD}

Division of Endoscopy, Shizuoka Cancer

Center, 1007, Shimonagakubo, Nagaizumicho, Suntogun, Shizuoka, 411-8777, Japan

Fax: +81-55-9895783

k.imai1977@gmail.com
[2] Ferlitsch M, Moss A, Hassan C et al. Colorectal polypectomy and endoscopic mucosal resection (EMR): European Society of Gastrointestinal Endoscopy (ESGE) Clinical Guideline. Endoscopy 2017; 49: 270-297

[3] Shiotsuki K, Imai K, Hotta K. Underwater endoscopic mucosal resection for complete R0 removal of an adenoma extending into the appendiceal orifice. Dig Endosc 2020; 32: e7-e8

[4] Shichijo S, Yamasaki Y, Takeuchi Y. Case of colonic adenoma involving a diverticulum resected by a traction-assisted endoscopic submucosal dissection technique. Dig Endosc 2017; 29: 729-730

[5] Hosotani K, Imai K, Hotta K et al. Underwater endoscopic mucosal resection for complete R0 removal residual adenoma at a perforated scar in patient with colostomy. Endoscopy 2017; 49: E121-E122

\section{Bibliography}

DOI https://doi.org/10.1055/a-1134-4668

Published online: 27.3.2020

Endoscopy 2020; 52: E374-E375

(c) Georg Thieme Verlag KG

Stuttgart · New York

ISSN 0013-726X

\section{ENDOSCOPY E-VIDEOS}

https://eref.thieme.de/e-videos

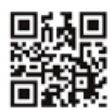

Endoscopy E-Videos is a free access online section, reporting on interesting cases and new techniques in gastroenterological endoscopy. All papers include a high quality video and all contributions are freely accessible online.

This section has its own submission website at https://mc.manuscriptcentral.com/e-videos 